\title{
Prestack Inversion Identification of Dolomite Reservoirs in the Fourth Member of the Sinian Dengying Formation in Moxi Area, Sichuan Basin, SW China
}

\author{
Yong Wu $\mathbb{D}^{1,}{ }^{1,2}$ Xuxu Wang, ${ }^{1}$ Lu Zhou, ${ }^{1,3}$ Chongyang Han, ${ }^{4}$ Lianjin Zhang, ${ }^{5}$ Xuemei Lan, \\ and Peng $\mathrm{Lu}^{6}$ \\ ${ }^{1}$ School of Geoscience and Technology, Southwest Petroleum University, Chengdu 610500, China \\ ${ }^{2}$ Sichuan Province Key Laboratory of Natural Gas Geology, Chengdu 610500, China \\ ${ }^{3}$ State Key Laboratory of Oil and Gas Reservoir Geology and Exploitation, Southwest Petroleum University, Chengdu 610500, China \\ ${ }^{4}$ Korla Branch of Bureau of Geophysical Prospecting Co., Ltd., CNPC, Korla 841000, China \\ ${ }^{5}$ Research Institute of Petroleum Exploration and Development, Southwest Oil and Gas Field Company, PetroChina, \\ Chengdu 610051, China \\ ${ }^{6}$ Southwest Branch, CNPC Logging Company Limited, Chongqing 400021, China
}

Correspondence should be addressed to Yong Wu; wycan_112@126.com

Received 23 October 2020; Accepted 2 August 2021; Published 6 September 2021

Academic Editor: Keyu Liu

Copyright ( 2021 Yong Wu et al. This is an open access article distributed under the Creative Commons Attribution License, which permits unrestricted use, distribution, and reproduction in any medium, provided the original work is properly cited.

\begin{abstract}
The dolomite reservoir of the fourth member of Dengying Formation in Moxi area of Sichuan Basin is thin, is fast in lateral variation, and has P-impedance difference from the surrounding rock; it is difficult to identify and predict the dolomite reservoir and fluid properties by conventional poststack seismic inversion. Through the correlation analysis of core test data and logging P-S-wave velocity, this work proposed a formula to calculate the shear wave velocity in different porosity ranges and solved the issue that some wells in the study area have no S-wave logging data. AVO forward analysis reveals that whether the gas reservoir of dolomite reservoir is located at the top of the fourth member of Dengying Formation is the main factor affecting the variation of AVO type. Through cross-plotting analysis of elastic parameters, it is found that P-S-wave velocity ratio and fluid factor are sensitive parameters to gas-bearing property of dolomite reservoir in the study area. By comparing the inversion results of prestack parameters such as density, P-wave impedance, S-wave impedance, P-S-wave velocity ratio, and fluid factor, it is found that the gas-bearing prediction of dolomite reservoir by using P-S-wave velocity ratio and fluid factor obtained from simultaneous prestack inversion had the highest coincidence rate with actual drilling data. At last, according to the distribution characteristics of fluid factor and P-S-wave velocity ratio, the favorable gas-bearing areas of dolomite reservoir in the fourth member of Dengying Formation in the study area are finely predicted, and the next favorable exploration areas were pointed out.
\end{abstract}

\section{Introduction}

Seismic inversion technology is based on seismic data to infer the spatial change and physical structure of the earth's internal media, understand the distribution of various rock geophysical parameters, estimate the reservoir parameters, and predict the reservoir, so as to provide favorable basis for oilfield exploration and development. The results of conventional poststack seismic inversion can reflect the internal variation characteristics of reservoir to a certain extent. However, due to the multiple superpositions of seismic data, the sensitive information of reservoir such as amplitude and travel time is lost, which has certain limitations in reservoir and fluid prediction. Compared with poststack seismic inversion, prestack seismic inversion has the advantages of fidelity and multi-information, and its results can more reliably predict the distribution, physical properties, and fluid properties of reservoir [1-4]. Prestack inversion technology through the 
continuous research of many scholars, from the early qualitative prediction to the present multiparameter quantitative prediction, provides technical support for the multidirectional quantitative prediction of different reservoirs. Shuey [5] proposed an approximate formula to transform prestack seismic data to obtain AVO attribute parameters. The prediction results lack the constraints of logging data, so this method can only be regarded as a qualitative reservoir identification method. Connolly [6] established an elastic wave impedance inversion method related to the incident angle, and there are also differences that cannot explain the inversion profile at different angles. Hampson et al. [7] proposed the prestack simultaneous inversion technology based on the Fatti approximation [8], which is an important innovation of prestack inversion technology. It not only restricts the seismic data from various angles but also improves the inversion stability and obtains the rock elastic parameters with physical significance [8-10]. With the development of computer algorithm technology, prestack inversion methods have also been widely used in quantitative prediction of reservoir parameters. Gan et al. [11] applied the concept of elastic wave impedance to Tertiary reservoirs in the Bohai Bay area and proposed that elastic impedance can reflect changes in fluid saturation. Zhang et al. [12] applied the prestack inversion technology to the sandstone layers in the Sulige area, proving that prestack seismic inversion is better than poststack inversion in sandstone identification. Chang et al. [13] used elastic impedance inversion to predict volcanic rock development areas and proved that the application effect of elastic impedance inversion in volcanic rock development areas in eastern Hebei is also better than conventional impedance inversion. Shelander et al. [14] established a lithology identification template for shallow waters in the Gulf of Mexico and predicted gas saturation for sandstone reservoirs. Prestack seismic inversion technology has achieved good applications in the prediction of sand and mudstone reservoirs, but there are still problems in its application in carbonate reservoirs. First, the influence of fluid in carbonate pores on velocity is less obvious than that of clastic rocks, which makes the fluid difficult to identify $[15,16]$. The second is that carbonate rocks are easy to be transformed by cementation, dissolution, and other diagenesis. Fractures are relatively developed, reservoir heterogeneity is strong, and physical properties change rapidly, which makes inversion results have multiple solutions $[17,18]$. Therefore, it is difficult to identify carbonate reservoirs by poststack inversion.

Moxi area is located in the central part of Sichuan Basin, which is located in the high part of Leshan-Longnusi paleo uplift (Figure 1). As a key breakthrough block of natural gas exploration in Sichuan Basin, seven exploration wells have been drilled in the study area since 2011, all of which have obtained industrial gas flow in the fourth member of the Sinian Dengying Formation, which proves that the Sinian Dengying Formation in this area has great oil and gas exploration and development potential. However, due to the complexity of dolomite reservoir and the multiple solutions of seismic identification, it is difficult to expand the exploration and development of gas reservoir. The main reasons are the following two aspects. First, the dolomite reservoirs of the
Dengying Formation in the study area are thin reservoirs with low porosity, and the $\mathrm{P}$-wave impedance of the reservoirs is less different from the surrounding rock. The conventional poststack seismic inversion method cannot accurately distinguish between reservoir and nonreservoir. Second, the Dengying Formation in the study area has a large burial depth, complex seismic response patterns of dolomite gas layers, and diverse understanding. Therefore, accurately establish the seismic geological response models corresponding to the different physical properties and gas-bearing properties of the dolomite reservoirs in the fourth member of the Sinian Dengying Formation, identify the dolomite reservoirs and predict the distribution of gas layers, and improve the success rate of gas reservoir drilling. The technical problems faced by the research area are also the focus of this article.

\section{Stratum Lithology and Seismic Reflection Characteristics}

The Sinian Dengying Formation in Sichuan Basin mainly developed limited platform facies. The whole set of strata experienced strong paracontemporaneous dolomitization, which provided the material basis for large-scale reservoir development [19]. The platform facies of the fourth member of Dengying Formation migrated eastward, and the platform margin facies developed in the study area (Figure 2), mainly microbial mound beach subfacies. The third submember of the fourth member of the Dengying Formation is dominated by light gray-brown, gray micrite-shaped algal clot dolomite, breccia dolomite, and algal stromatolite. The reservoirs are relatively developed, mainly microbial mound-shoal sediments, with well-developed pores. The second submember of the fourth member of Dengying Formation is composed of gray-brown mud-silver crystal dolomite interbedded with gray-brown algal stromatolite and algal clot dolomite, and its reservoirs have poor storage performance. The first submember of the fourth member of Dengying Formation is dominated by dark gray and brown argillaceous algal clotbearing dolomite and micrite dolomite, and the reservoirs in this submember are relatively underdeveloped.

The thin karst dolomite reservoirs in the study area are mainly developed on the top of the Sinian Dengying Formation, showing the characteristics of thin layers and multiple sets in the vertical direction. The pore types of karst reservoirs are mainly fractures, pores, and karst cave storage spaces, including fracture-porous reservoirs and porous reservoirs [20]. As the Dengying Formation was deposited in a platform sedimentary environment at the beginning, it was later affected by structural uplift. The stratum was denuded to develop epigenetic karst. In the later period, a large number of fractures were formed by multiple tectonic movements, which improved the reservoir performance to a certain extent. Permeability. The permeability and porosity of dolomite reservoirs in the fourth member of Dengying Formation in Moxi area are relatively low, and the fracturevug reservoir is the better reservoir type in the study area.

The top of the fourth member of the Dengying Formation (the top of the Dengying Formation) has strong to medium-strong amplitude peak reflections, with obvious 


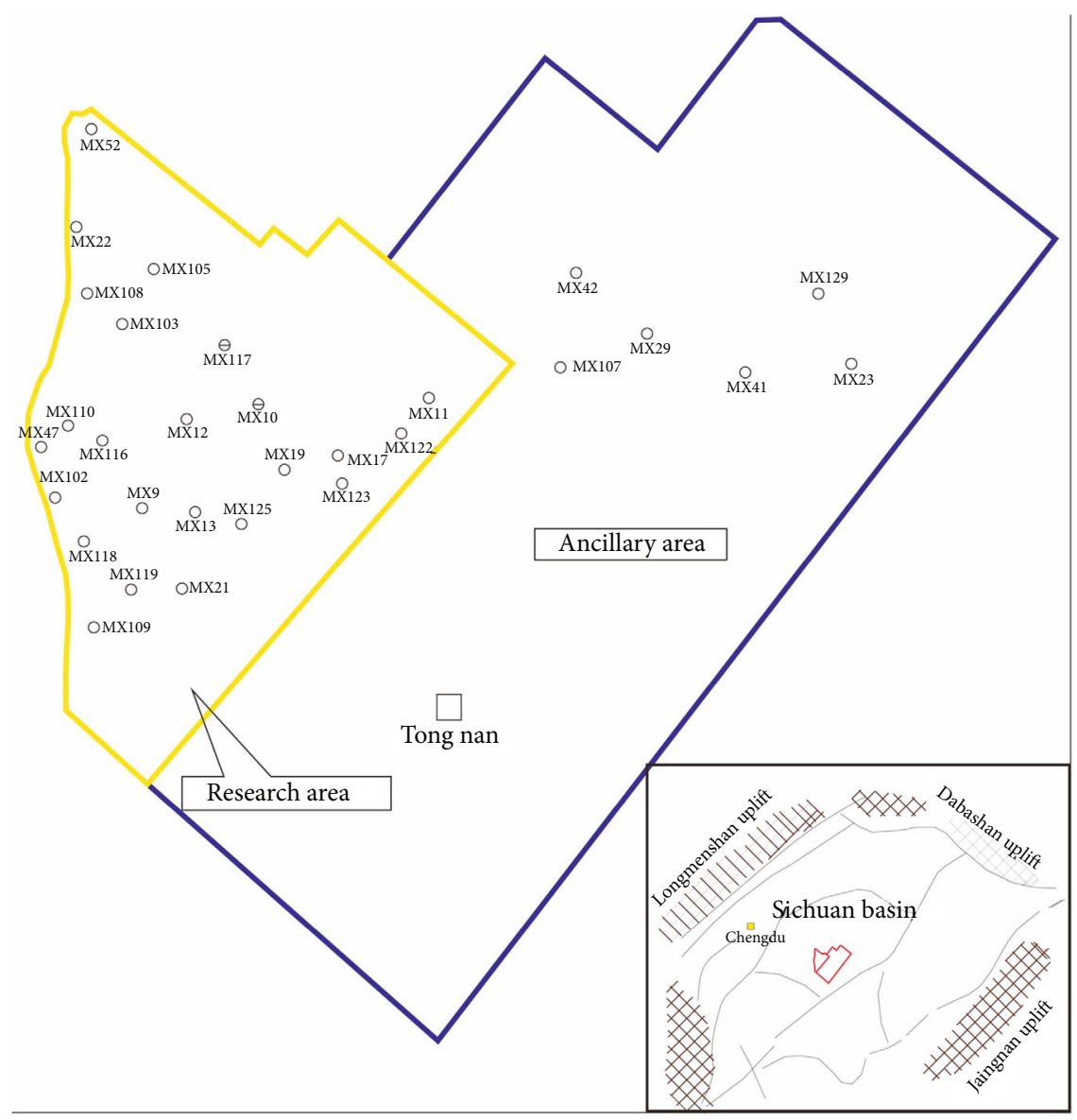

Figure 1: Location map of the study area.

lateral spreading characteristics in the whole area, and relatively weak amplitude reflection characteristics in the local area (Figure 3). The bottom is dominated by strongamplitude trough reflections. Due to the superimposed influence of coastal karstification in the entire Moxi area, the quality of reservoir development has the characteristic of gradually deteriorating from the platform margin belt to the platform along the direction perpendicular to the steep ridge belt [21].

Through the intersection analysis of reservoir petrophysical parameters, the gas layer, poor gas layer, and dry layer in the study area are obviously overlapped in the range of P-wave impedance $16000 \sim 19000 \mathrm{~m} \cdot \mathrm{g} /\left(\mathrm{cm}^{3} \cdot \mathrm{s}^{-1}\right)$, and it is difficult to distinguish reservoir and nonreservoir (Figure 4). If the $\mathrm{P}$-wave impedance is used to interpret the reservoir, there may be multiple solutions, so the poststack wave impedance inversion method has limitations in the reservoir prediction process of the study area. However, on the horizontal axis of the cross-plot (Figure 4), when the P-S-wave velocity ratio is 1.7 , the reservoir and nonreservoir can be distinguished. Due to the partial overlap between gas reservoir and poor gas reservoir, the P-S-wave velocity ratio between 1.55 and 1.7 is poor gas reservoir and 1.4 and 1.65 is gas reservoir, which indicates the importance of S-wave information and the feasibility of prestack inversion in identifying reservoirs of Dengying Formation in Moxi area.

\section{Method}

Compared with the poststack inversion method, the prestack inversion method based on $\mathrm{P}$-wave and S-wave velocity information can effectively identify and predict the dolomite reservoir in the study area by using more parameter information. According to the results of prestack multiparameter simultaneous inversion, not only can the multisolution of reservoir prediction be reduced but also the quantitative analysis of multiparameters can be used to confirm each other and realize the quantitative prediction of reservoir. Swave information plays an important role in prestack inversion. Therefore, accurate estimation of S-wave velocity for wells without $\mathrm{S}$-wave data is a key step in prestack inversion.

\subsection{Estimation of $S$-Wave Velocity Using P-Wave Velocity.} Because the velocity of $\mathrm{P}$-wave decreases obviously after passing through the gas-bearing reservoir, but the velocity of Swave does not change obviously, so the velocities of $\mathrm{P}$-wave and S-wave are the key parameters for reservoir and fluid identification and prediction, and the velocity of S-wave plays an important role in petrophysical analysis and AVO forward modeling [22-24]. The quality of S-wave curve is difficult to control, so it is necessary to effectively predict Swave velocity through petrophysical experiment and logging curve intersection analysis [25]. Through statistical analysis 


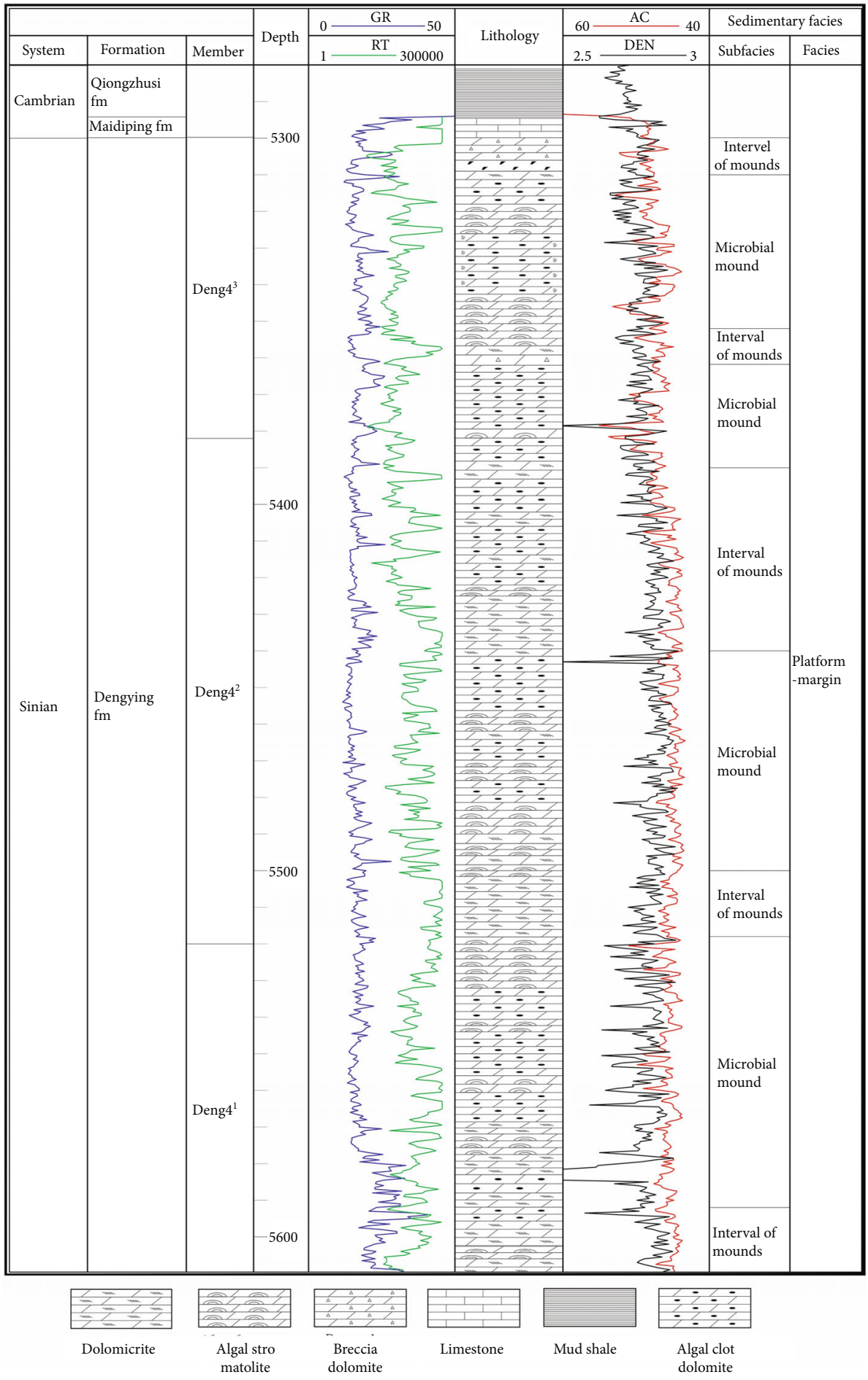

FIgURE 2: Composite stratigraphic column of well MX105.

of petrophysical test results and logging interpretation data, the reservoir at the top of Dengying Formation in the study area is characterized by low porosity and low permeability. The porosity of the fourth member of Dengying Formation in the study area is mainly $2 \%-6 \%$ (Figure 5 ). There is a positive correlation between porosity and gas production. For example, in well MX22 (Figure 6(a)) with well-developed reservoir, porosity is concentrated in $4 \%-6 \%$ with good gas- bearing property; in well MX12 (Figure 6(b)) with poor reservoir development, porosity is concentrated in $2 \%-4 \%$, with poor gas-bearing property; and the lower limit of porosity of effective reservoir is $2 \%$.

In order to further clarify the relationship between Pwave velocity and S-wave velocity in dolomite reservoir of Dengying Formation and provide specific calculation formula for S-wave estimation, we counted the logging porosity 


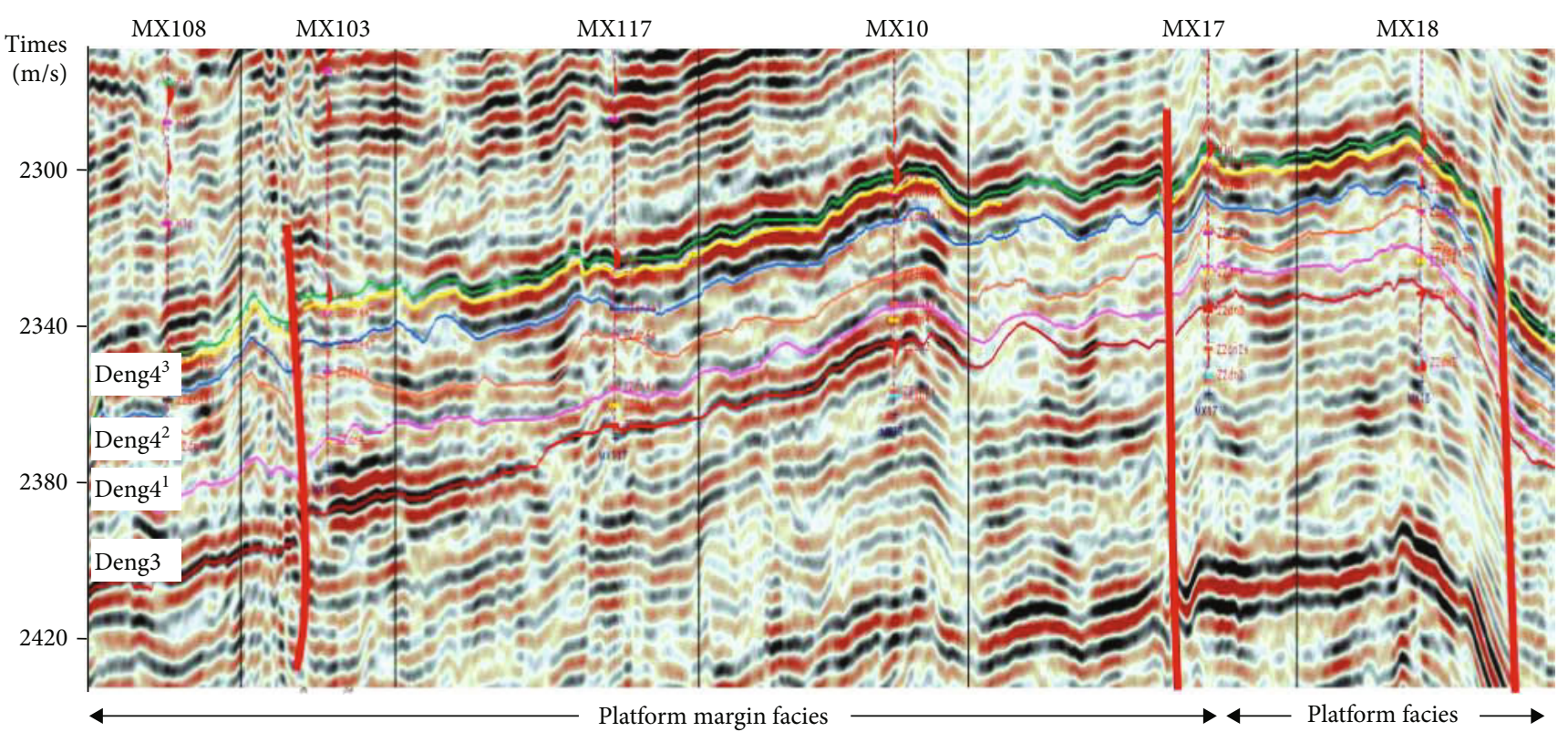

FIgURE 3: Seismic correlation profile of connected wells.

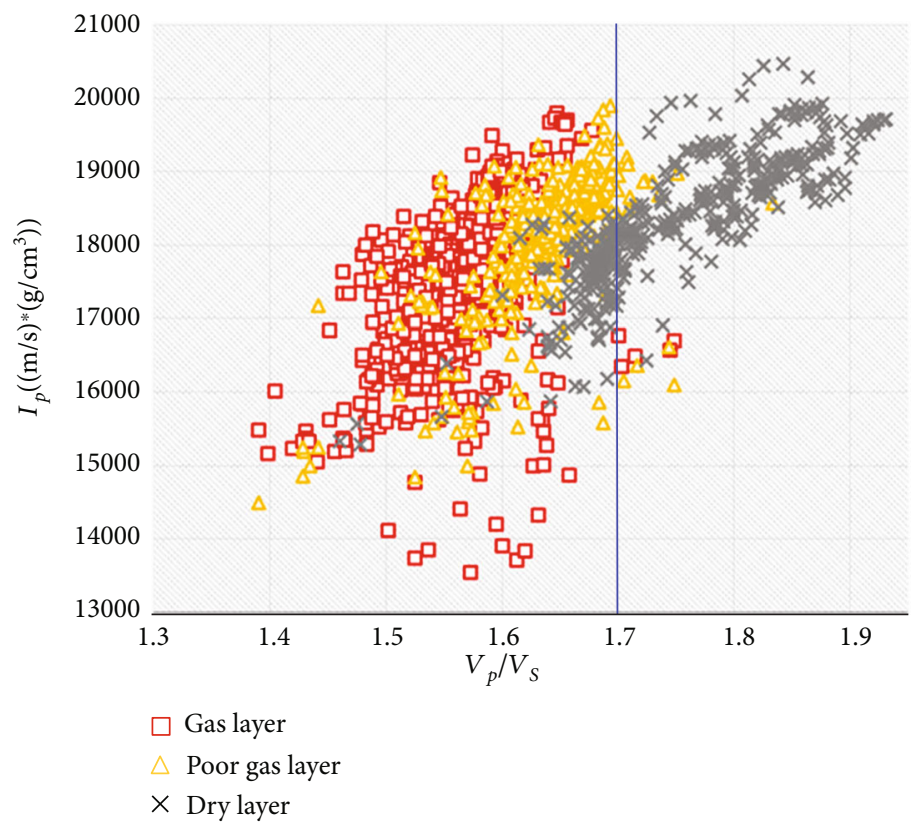

Figure 4: Cross-plot of P-S-wave velocity ratio and P-wave impedance.

distribution of wells with S-wave data in Dengying Formation (Figure 7). The porosity of dolomite reservoirs is mainly distributed between $2 \%$ and $8 \%$, only a small part is greater than $8 \%$, and the porosity of nonreservoir is less than $2 \%$. The intersection analysis of the $\mathrm{P}$-wave and $\mathrm{P}$-wave velocities under different porosities (Figure 7) shows that the velocity of $\mathrm{P}$-wave and $\mathrm{S}$-wave in different porosity has distinct zonation. According to the reservoir porosity and permeability characteristics of the fourth member of Dengying Formation in the study area, the Krief model suitable for medium and low porosity formation is selected [26]. The relationship between S-wave velocity $\left(V_{s}\right)$ and P-wave velocity $\left(V_{p}\right)$ is as follows:

$$
V_{s}^{2}=a V_{p}^{2}-b
$$

Table 1 shows the formulas for calculating S-wave velocity in different porosity intervals of the study area. In order to verify the estimation effect of the fitting formula of S-wave calculation, the single porosity formula and comprehensive porosity formula are applied to estimate the S-wave of the 


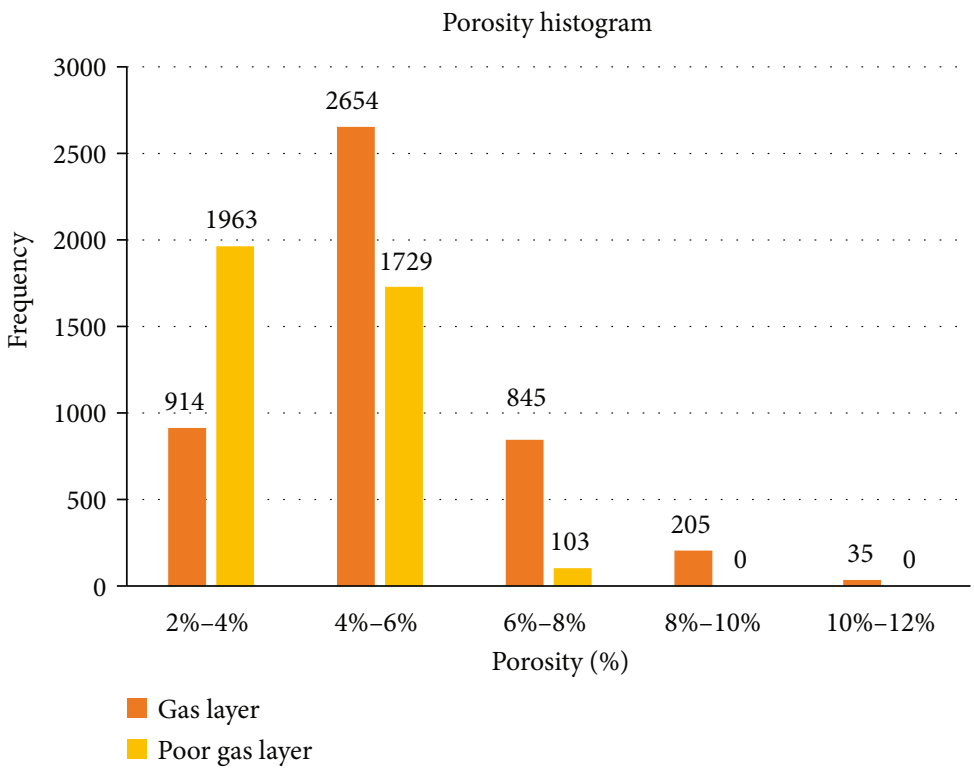

Figure 5: Porosity statistical histogram of the fourth member of Dengying Formation.

fourth member of Dengying Formation in well MX109 (Figure 8). Compared with the S-wave data calculated by single porosity formula, the S-wave data calculated by the comprehensive porosity formula has greater similarity with the measured S-wave data. Moreover, the algorithm is relatively simple and easy to implement, which indicates that it is feasible to use the S-wave estimation method based on porosity interval in the fourth member of Dengying Formation in the study area.

\subsection{Analysis of Dolomite Reservoir and Fluid Sensitivity} Parameters. The petrophysical theory is the bridge between seismic data and reservoir parameters, and the theoretical basis of seismic reservoir research, lithology identification, and oil and gas detection [22]. Due to the importance of Swave information for reservoir and fluid identification and prediction, a variety of rock elastic parameters are extracted and optimized to find the sensitive parameters of the fourth member of the Dengying Formation in the study area, which are applied to prestack inversion to improve the accuracy of prediction results $[27,28]$. The fluid factor, as an important parameter reflecting the properties of fluid contained in the reservoir $[29,30]$, is generally written as a function of Pwave impedance and S-wave impedance.

$$
\lambda_{\rho}=I_{p}^{2}-2 I_{s}^{2}
$$

The intersection analysis of petrophysical parameters for key wells in the study area shows that the P-S-wave velocity ratio is a more sensitive parameter to identify reservoirs and nonreservoirs (Figure 9). The P-S velocity ratio range of gas reservoir is 1.4-1.7, while that of nonreservoir is 1.622 (Figure $9(\mathrm{c})$ ). Fluid factor $\left(\lambda_{\rho}\right)$ is the most sensitive parameter for gas-bearing property identification of reservoir. There is a clear dividing line between the gas layer and the poor gas layer in the study area when the fluid factor is $\lambda_{\rho}$ $=150$, and the superposition of them is greatly improved (Figure $9(\mathrm{~d})$ ). The velocity ratio of $\mathrm{P}$-wave and S-wave and fluid factor are sensitive to the identification of gas-bearing property of reservoir, but there is still a small overlap, which may cause some errors to the inversion results.

3.3. AVO Forward Analysis. AVO forward analysis mainly refers to using model forward modeling to simulate AVO phenomenon. Combined with the characteristics of gas reservoir in the study area, the range of parameters of different lithology in the fourth member of Dengying Formation is counted, and the density of surrounding rock is $2.81 \mathrm{~g} / \mathrm{cm}^{3}$, $\mathrm{P}$-wave velocity is $6630 \mathrm{~m} / \mathrm{s}$, and $\mathrm{S}$-wave velocity is $3556 \mathrm{~m} / \mathrm{s}$. According to the buried depth and average velocity of the fourth member of Dengying Formation, the maximum incident angle is $40^{\circ}$ calculated by a ray-tracing method [31], and the AVO trend recognition chart of dolomite reservoir in the study area is obtained by forward modeling (Table 2). There are three AVO trends of types I, III, and IV on the top of dolomite reservoir in the study area. The AVO characteristics of type I are that the polarity of reflection coefficient is negative, and the amplitude is greater than zero and decreases with the increase of incident angle, intercept $P>0$ , and gradient $G<0$. Most of the gas reservoir in the study area are type I AVO characteristics. In the forward modeling, the reflection coefficient polarity of the type III AVO is negative, and the amplitude increases with the increase of incident angle, intercept $P<0$, gradient $G<0$. AVO feature of water layer is type IV AVO, in forward modeling, the polarity of reflection coefficient is negative, and the amplitude increases with the increase of incident angle. The wave impedances of gas reservoir and water layer are lower than those of nonreservoir, in which type I AVO corresponds to the reservoir at the top of the fourth member of Dengying Formation (such as wells MX22, MX105, and MX109). The 


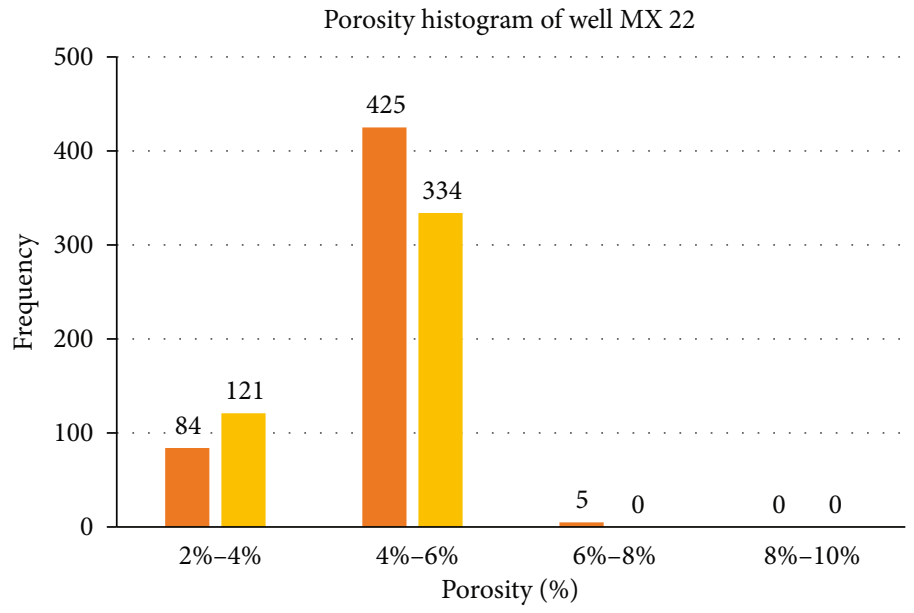

Gas layer

Poor gas layer

(a)

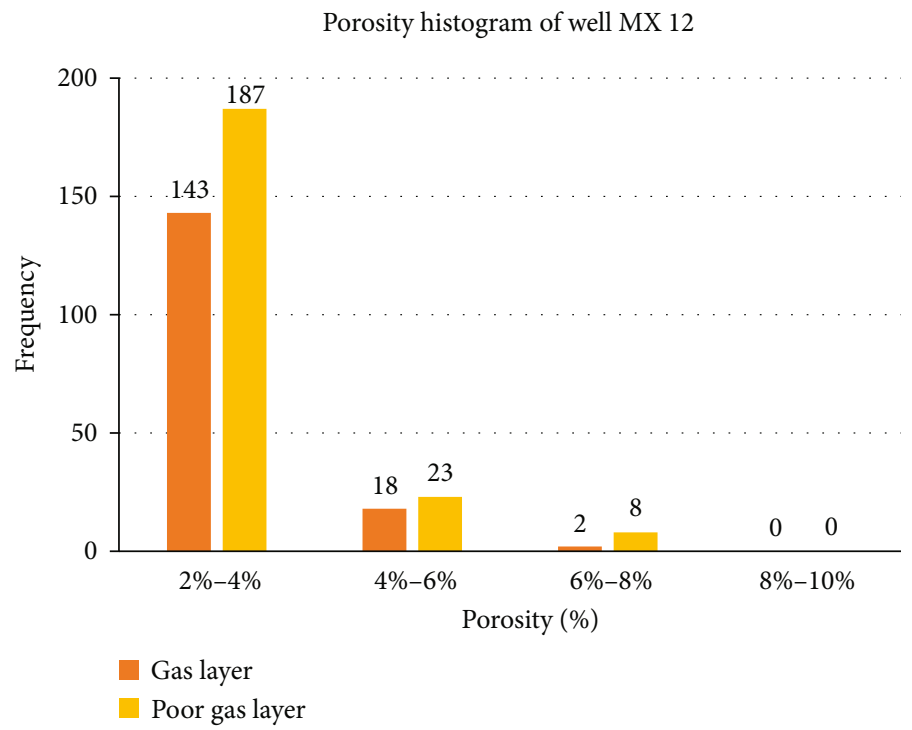

(b)

FIgure 6: Porosity statistical histogram of the fourth member of Dengying Formation in wells MX22 and MX12.

type III AVO corresponds to the reservoir in the middle and upper part of the fourth member of Dengying Formation (such as well MX103), and the water layer has only the AVO characteristics of type IV.

Through the analysis of single well petrography and drilling data in the study area, the gas reservoir with AVO response type I is located at the top of the fourth member of Dengying Formation. The gas reservoir with AVO response type III is located about $50 \mathrm{~m}$ away from the top of Dengying Formation. Therefore, it can be inferred that the different AVO types of gas reservoir in the study area may be caused by whether the reservoir is located at the top of Dengying Formation.

\section{Result}

4.1. Prestack Inversion Analysis of Dolomite Reservoir. Simultaneous prestack inversion based on the Fatti approximation and convolution model can directly obtain density, P-wave impedance, and S-wave impedance and, at the same time, perform reservoir porosity inversion and gas-bearing detection, which is a quantitative study method [10, 32-35]. By establishing an inversion model, verifying the logarithmic relationship coefficients between $\mathrm{P}$-wave impedance, $\mathrm{S}$ wave impedance, and density, setting the time length, spatial range, and format of the generated data volume, etc., and finally, the inversion result data of $\mathrm{P}$-wave impedance, $\mathrm{S}$ wave impedance, and density is generated. In the profile of prestack density inversion result (Figure 10), obvious red low-value anomaly appears in the test profile of the fourth member of Dengying Formation in well MX22 and well MX105, which has good recognition for dolomite reservoir, and sporadic yellow low-value anomaly for wells MX116 and MX102 with poor reservoir physical properties, but the gas reservoir test profile of middle well MX103 is not identified. The results of P-wave impedance inversion (Figure 11) 

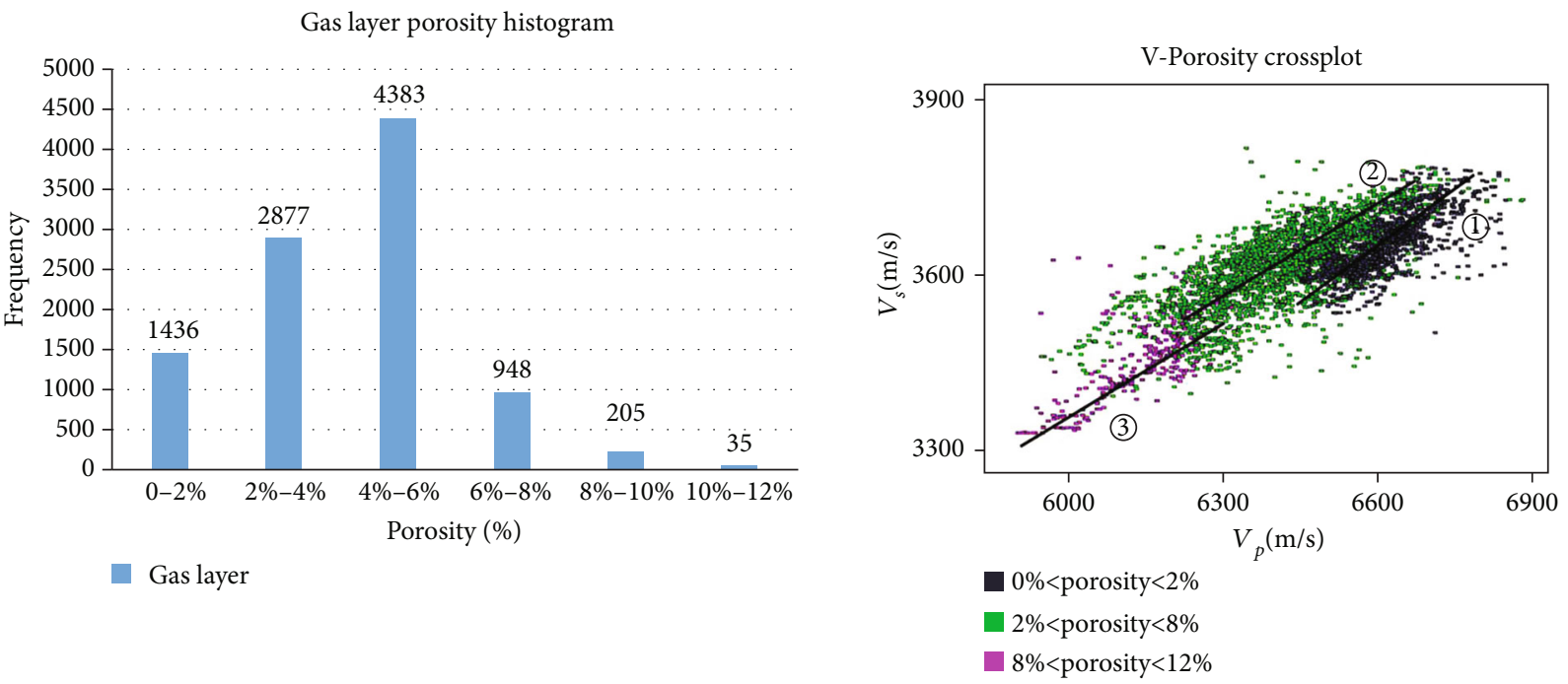

FIgURE 7: Logging data analysis diagram of the fourth member of Dengying Formation.

TABLE 1: Formulas for calculating S-waves based on porosity.

\begin{tabular}{lcc}
\hline Classification & Porosity interval & S-wave calculating formula \\
\hline Formula one (low porosity) & $0 \%<$ formation porosity $<2 \%$ & $V_{s}^{2}=0.365 V_{p}^{2}+698.41$ \\
Formula two (medium porosity) & $2 \%<$ formation porosity $<8 \%$ & $V_{s}^{2}=0.3525 V_{p}^{2}+2873.54$ \\
Formula three (high porosity) & $8 \%<$ formation porosity $<12 \%$ & $V_{s}^{2}=0.348 V_{p}^{2}+1964.71$ \\
\hline
\end{tabular}

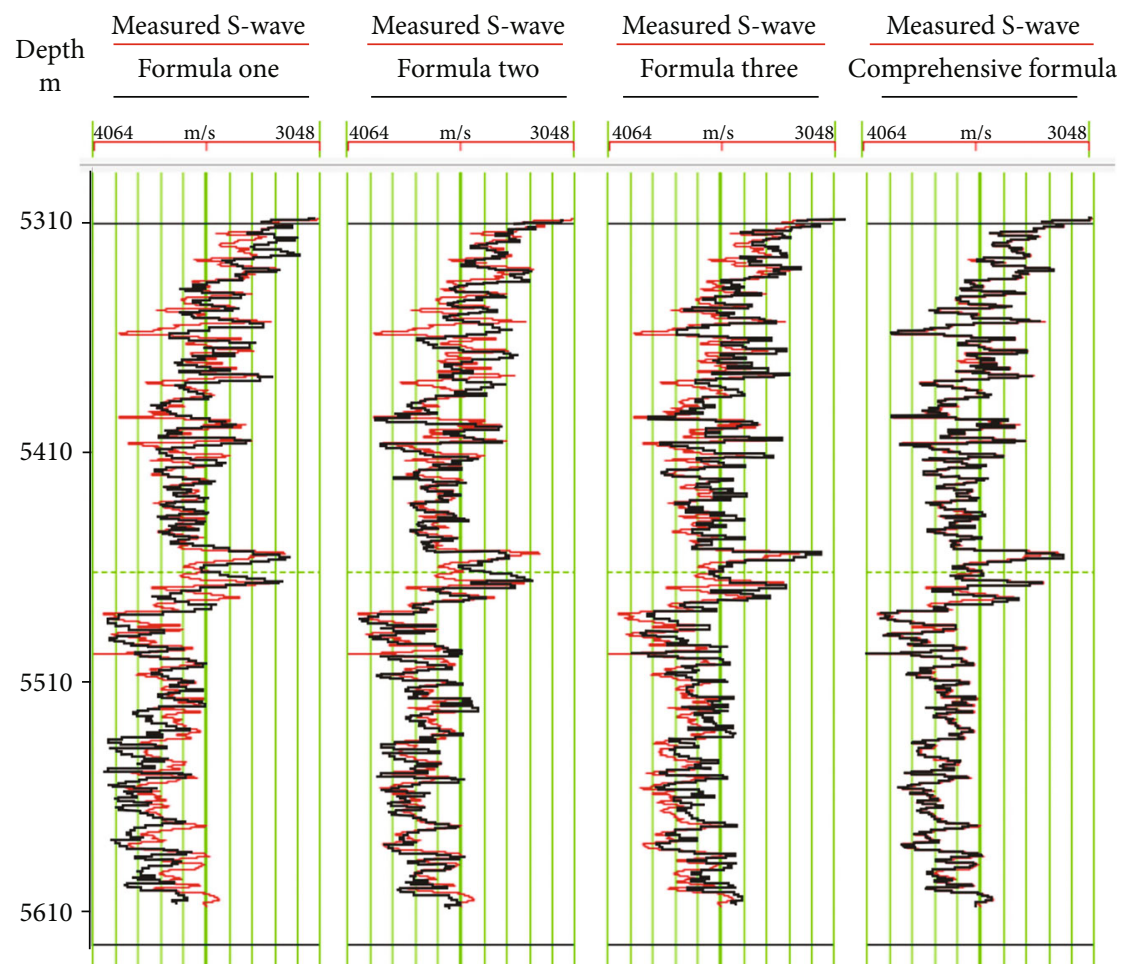

Figure 8: Comparison of S-wave fitting results of well MX109. 


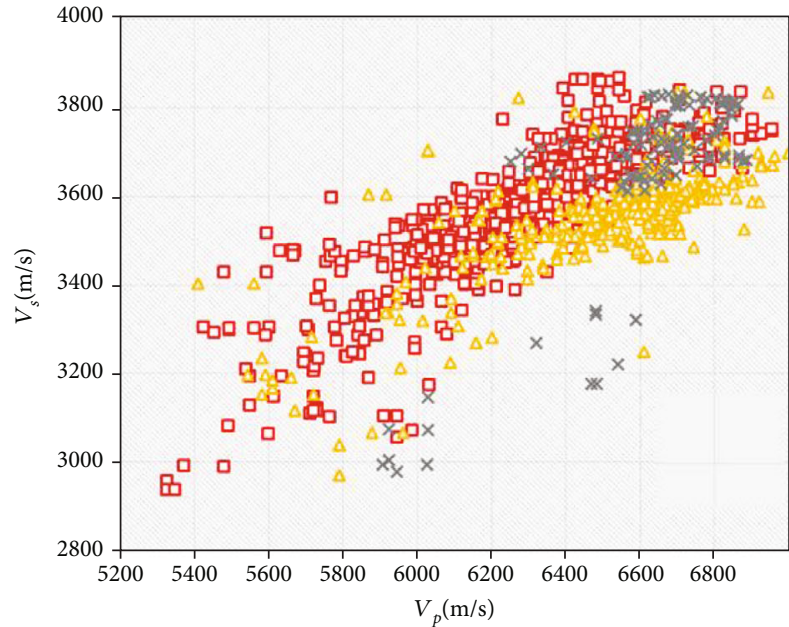

(a)

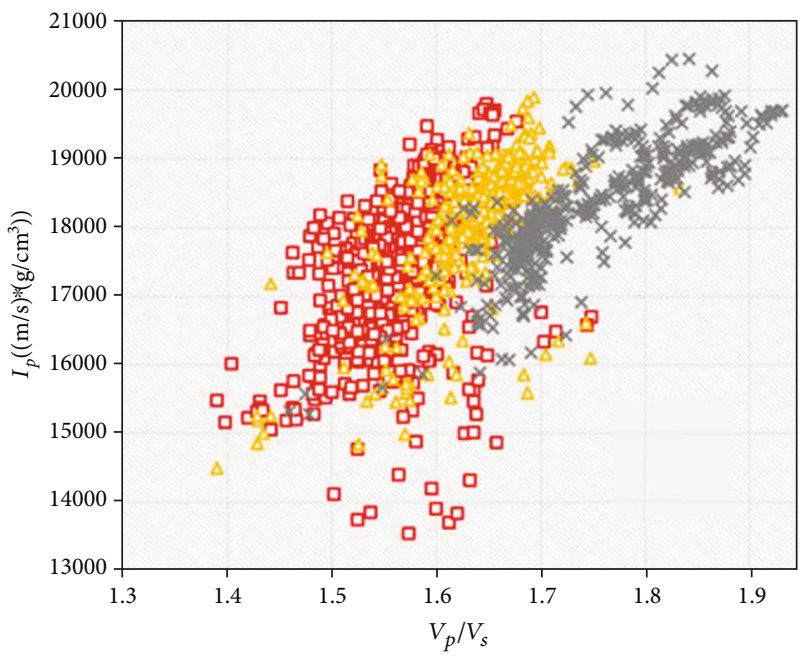

(c)

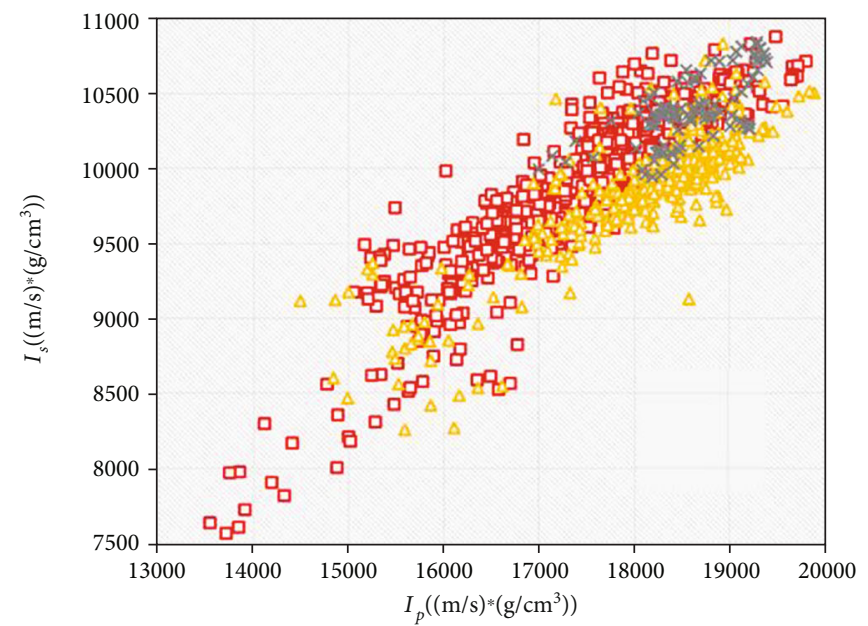

(b)

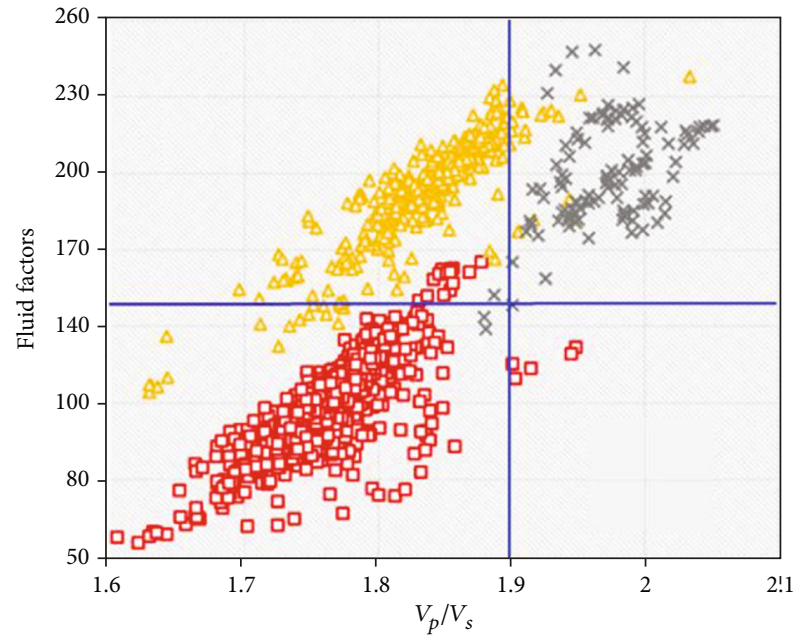

(d)

\section{$\square$ Gas layer \\ $\triangle$ Poor gas layer \\ $\times$ Dry layer}

FIGURE 9: Sensitivity analysis of reservoir and fluid petrophysical parameters in the study area. (a) Cross-plot of P-wave velocity and S-wave velocity. (b) Cross-plot of P-wave impedance and S-wave impedance. (c) Cross-plot of P-S-wave velocity ratio and P-wave impedance. (d) Cross-plot of P- and S-wave velocity ratio and fluid factor $\lambda_{\rho}$.

are basically consistent with the density inversion profile. The high-yield well MX22 and the middle production well MX105 are well recognized, but the gas reservoir identification of the middle production well MX103 is still poor. In the S-wave impedance inversion profile (Figure 12), only MX105 well has a good identification effect, and the identification results of each well are obviously different from the actual drilling results.

A comparative analysis of the dolomite reservoir and fluid sensitivity parameters of the fourth member of the Dengying Formation in the study area, the sensitive parameters are the $\mathrm{P} / \mathrm{S}$-wave velocity ratio and the fluid factor, which can better distinguish dolomite reservoirs from dolomite nonreservoir. The velocity ratio of $\mathrm{P}$-wave and $\mathrm{S}$-wave in the gas layer is 1.4-1.65, and that of nonreservoir is $1.65-2$.
The fluid factor can further identify the gas-bearing and water-bearing reservoirs in the study area. The fluid factor of the gas-bearing reservoir is about 50-150, and the fluid factor of the water layer is $150-250$.

The inversion results (Figures 13 and 14) show that the PS velocity ratio of wells MX22 and MX105 is a red low-value anomaly at the top of Dengying Formation, while the yellow low-value anomaly appears in the lower submember of the fourth member of Dengying Formation in wells MX22, MX105, MX103, and MX116, indicating that the reservoir is developed but the physical property is poor. At the same time, the reservoir at the top of the fourth member of Dengying Formation in MX103 well can not be identified by P-wave impedance, S-wave impedance, and density. The yellow lowvalue anomaly of the lower member of the fourth member of 
TABLE 2: AVO types of reservoirs in the study area.

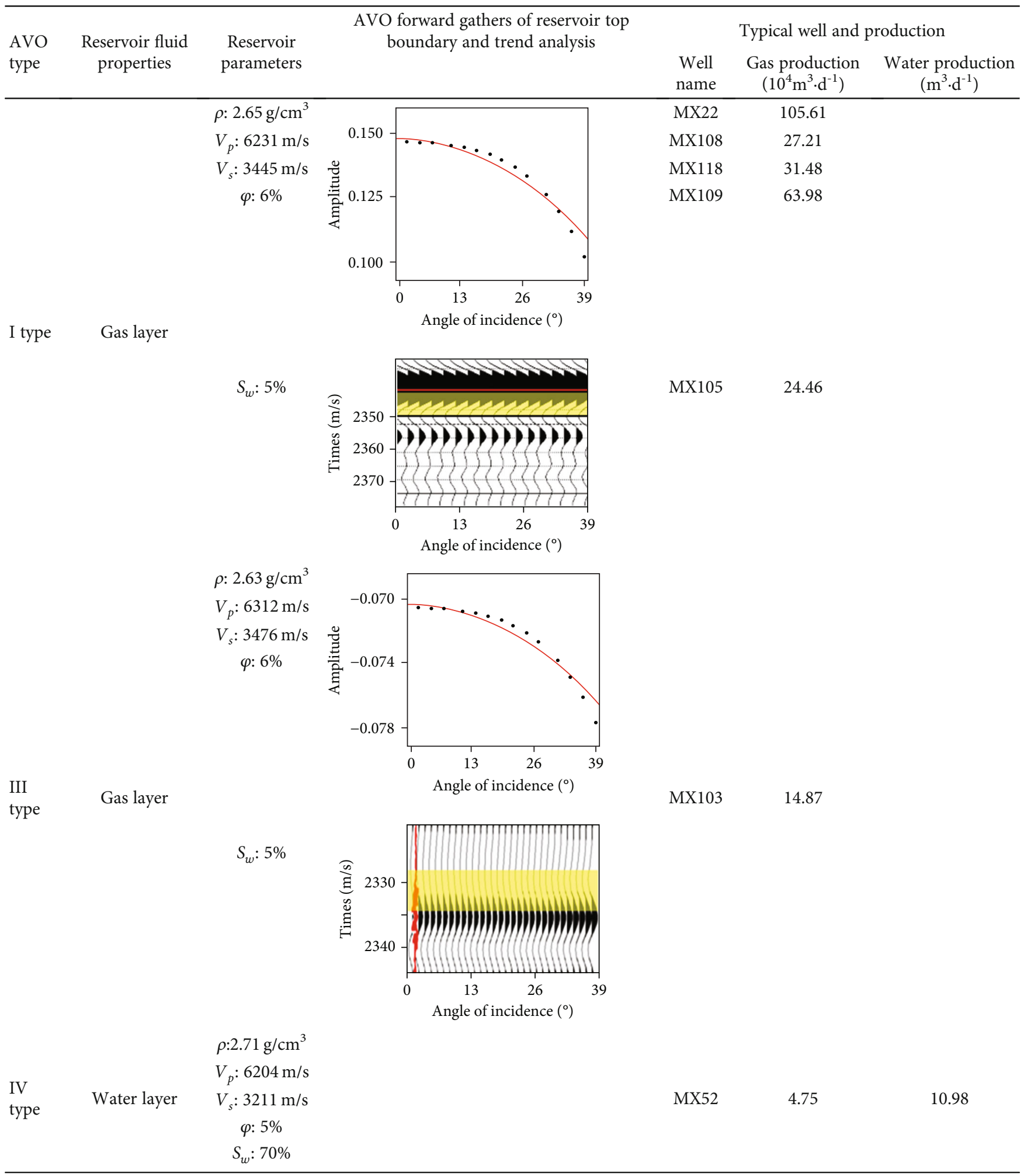


TABLe 2: Continued.
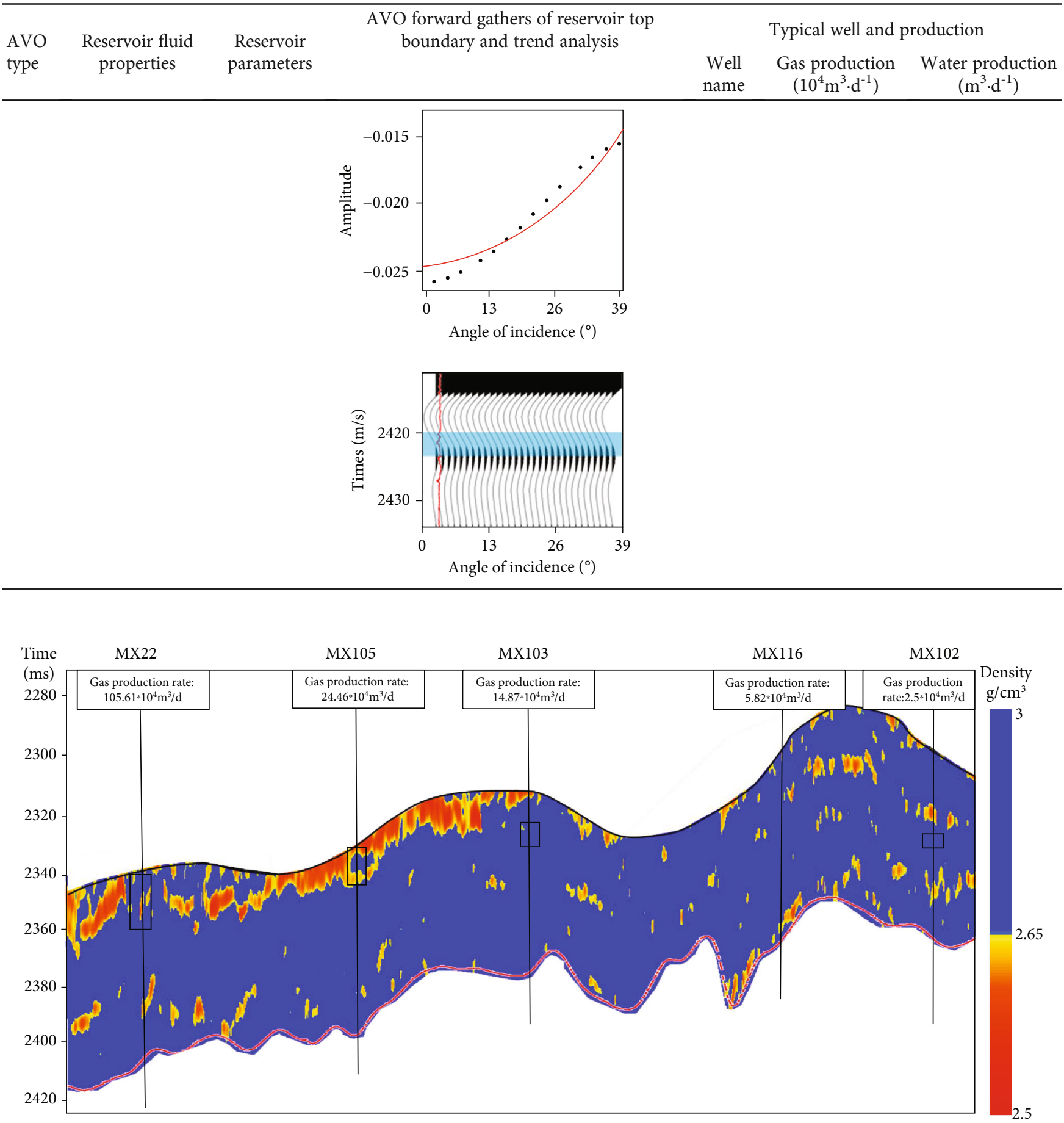

$\square$ Gas testing section

FIGURE 10: Prestack density inversion profile of the fourth member of Dengying Formation.

Dengying Formation in MX22 well is shown as water layer according to drilling data, which is also well distinguished in the fluid factor inversion profile. After excluding the influence of test scale, acid fracturing, and perforation size on the production of each well, the P-S-wave velocity ratio and fluid factor can be used as the indication parameters of gas-bearing capacity of dolomite reservoir in the fourth member of Dengying Formation.

Based on the comprehensive analysis of prestack simultaneous inversion results, the coincidence rate of actual drilling data and prestack inversion results of various parameters is statistically compared (Table 3 ). The dolomite reservoir 


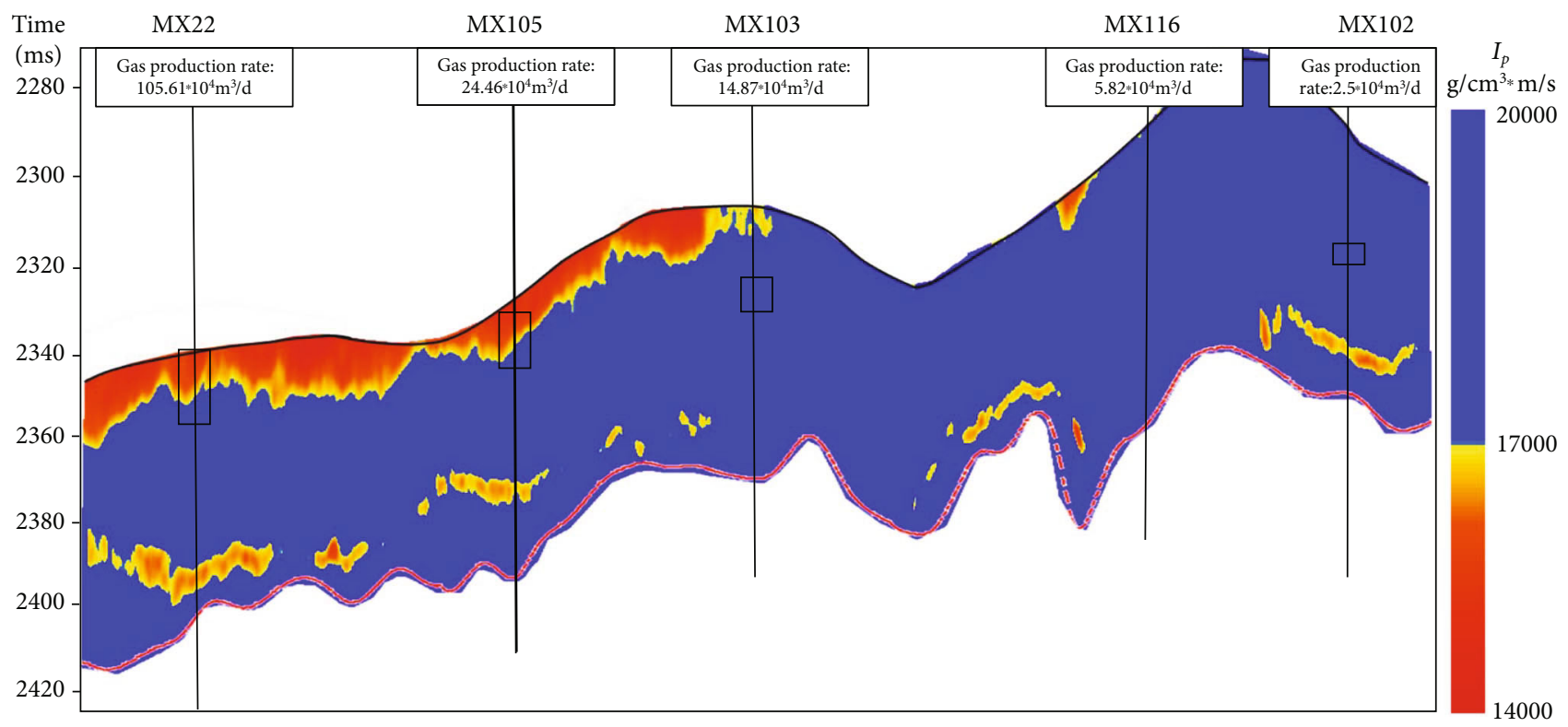

$\square$ Gas testing section

FIGURE 11: Prestack P-wave impedance inversion profile of the fourth member of Dengying Formation.

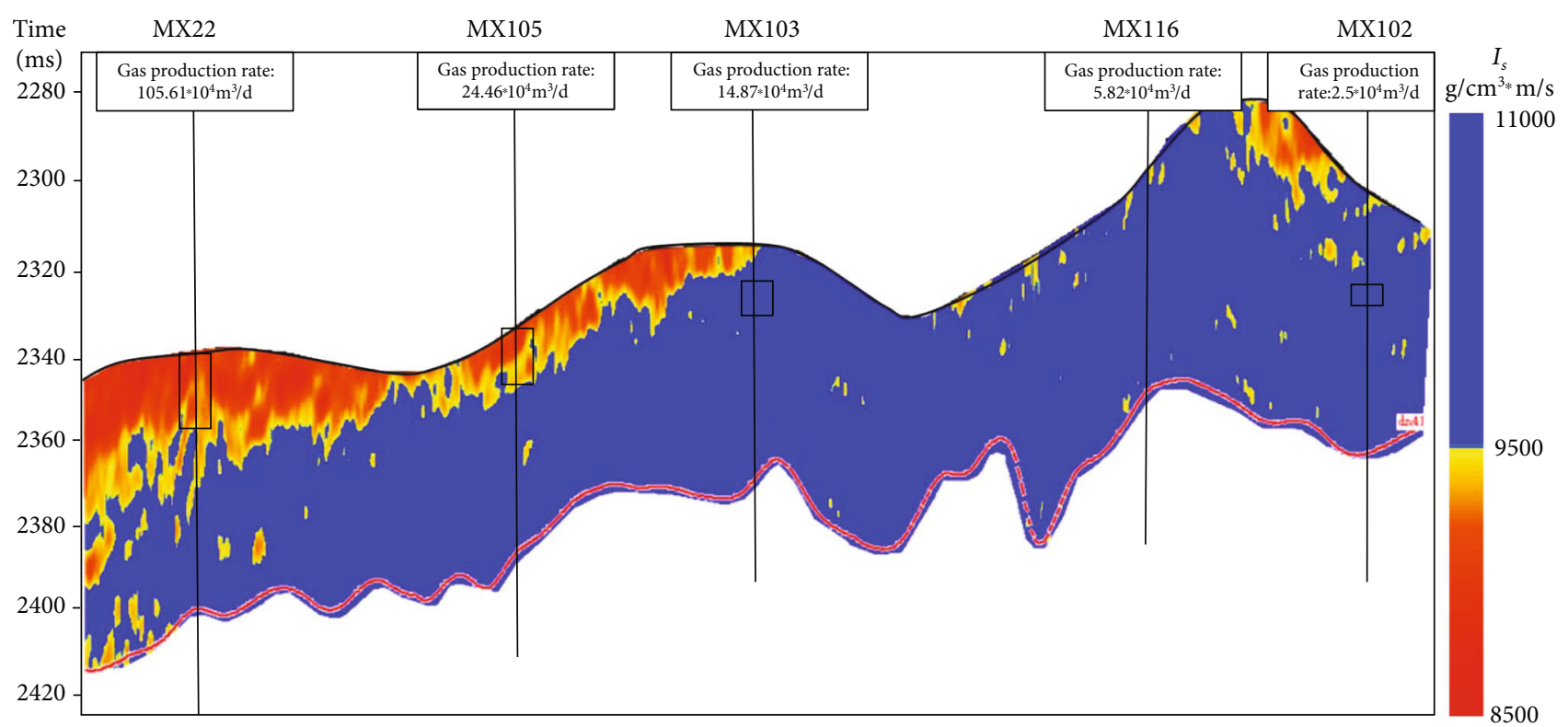

$\square$ Gas testing section

FIgURE 12: Prestack S-wave impedance inversion profile of the fourth member of Dengying Formation.

identified by S-wave impedance has the lowest coincidence rate with the actual drilling, and the inversion results of $\mathrm{P}$ $\mathrm{S}$-wave velocity ratio and fluid factor have the highest coincidence rate with drilling interpretation results. Therefore, the inversion results of P-S-wave velocity ratio and fluid factor are more consistent with the logging interpretation and drilling production results in the study area. The sensitivity of density and S-wave impedance to the reservoir in the study area is poor, and there are some multisolutions. Simultaneous prestack inversion is of great significance to the identification of dolomite reservoirs and gas-water in the study area. The research results of this method can be used as a direct basis for the prediction of favorable gas-bearing areas in dolomite reservoirs.

4.2. Comprehensive Prediction of Favorable Gas-Bearing Areas. The prestack simultaneous inversion method is used to maximize the use of seismic information and increase the accuracy of lateral extrapolation. However, due to the restriction of seismic frequency band, the vertical resolution is lower than that of logging, so the detail changes of some thin reservoirs are not fully shown. But the results of P-S- 


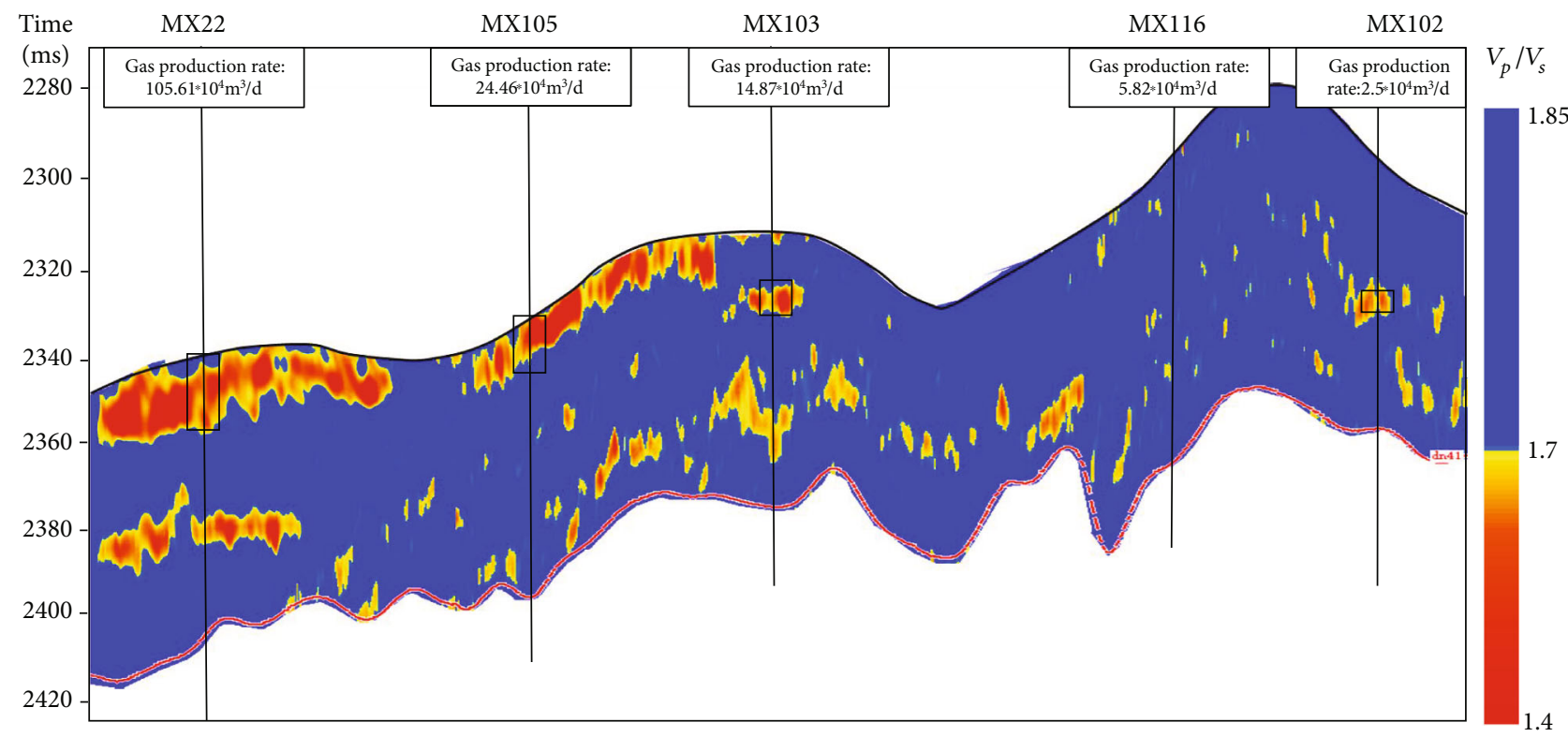

$\square$ Gas testing section

FIgURe 13: Prestack P-S-wave velocity ratio inversion profile of the fourth member of Dengying Formation.

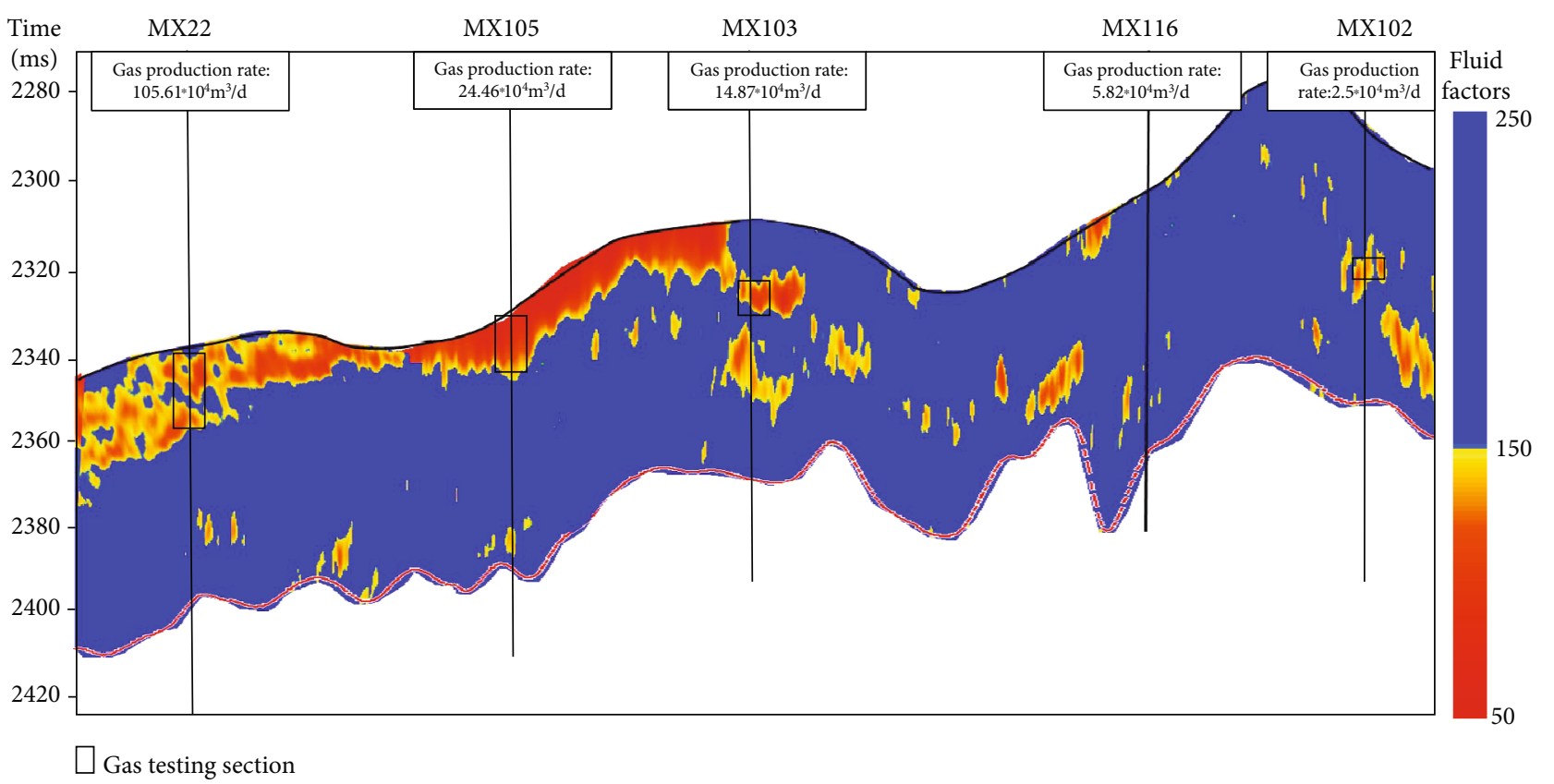

Figure 14: Prestack fluid factor $\left(\lambda_{\rho}\right)$ inversion profile of the fourth member of Dengying Formation.

wave velocity ratio and fluid factor are basically consistent with the logging interpretation results of each well. At the same time, AVO attribute analysis is applied to the inversion process, and the logging data are used to constrain, so as to improve the accuracy of reservoir and fluid identification. AVO gas-bearing indicator factor was used to detect the average gas-bearing capacity of the upper submember of the fourth member of Dengying Formation, and the planar distribution map of gas-bearing indicator factor was obtained (Figure 15(a)). The good range of gas-bearing property showed negative abnormal characteristics. Based on the P-
S-wave velocity ratio data volume obtained by prestack simultaneous inversion, the average amplitude value of $10 \mathrm{~ms}$ downward from the top of Dengying Formation is extracted, and the planar distribution map of P-S-wave velocity ratio in prestack inversion is obtained (Figure 15(b)). The P-S-wave velocity ratio of 1.4-1.65 is defined as gas reservoir, and the gas-bearing indicator factor of dolomite reservoir is highly consistent with the plane distribution of P-S-wave velocity ratio, which indicates that the prestack simultaneous inversion is of great significance for thin dolomite reservoir and gas water identification in the study area. 
TABLE 3: Statistical table of coincidence rate between the fourth member of Dengying Formation prestack simultaneous inversion results and drilling interpretation.

\begin{tabular}{|c|c|c|c|c|c|c|}
\hline Well & Fluid properties & Density $\left(\mathrm{g} / \mathrm{cm}^{3}\right)$ & $\begin{array}{c}I_{p} \\
\mathrm{~g} / \mathrm{cm}^{3} * \mathrm{~m} / \mathrm{s}\end{array}$ & $\begin{array}{c}I_{s} \\
\mathrm{~g} / \mathrm{cm}^{3} * \mathrm{~m} / \mathrm{s}\end{array}$ & $V_{p} / V_{s}$ & Fluid factors \\
\hline MX22 & Gas layer & Coincident & Coincident & Coincident & Coincident & Coincident \\
\hline MX105 & Gas layer & Coincident & Coincident & Coincident & Coincident & Coincident \\
\hline MX103 & Gas layer & Not coincident & Not coincident & Not coincident & Coincident & Coincident \\
\hline MX109 & Gas layer & Coincident & Coincident & Coincident & Coincident & Coincident \\
\hline MX119 & Gas layer & Coincident & Coincident & Coincident & Coincident & Coincident \\
\hline MX118 & Gas layer & Not coincident & Coincident & Coincident & Coincident & Coincident \\
\hline MX102 & Poor gas layer & Coincident & Not coincident & Not coincident & Coincident & Coincident \\
\hline MX116 & Poor gas layer & Coincident & Coincident & Coincident & Not coincident & Coincident \\
\hline MX10 & Poor gas layer & Coincident & Coincident & Coincident & Coincident & Coincident \\
\hline MX110 & Poor gas layer & Not coincident & Not coincident & Not coincident & Coincident & Not coincident \\
\hline MX13 & Poor gas layer & Coincident & Coincident & Coincident & Coincident & Coincident \\
\hline MX12 & Poor gas layer & Coincident & Coincident & Not coincident & Coincident & Coincident \\
\hline MX125 & Gas layer & Coincident & Coincident & Coincident & Coincident & Coincident \\
\hline \multicolumn{2}{|c|}{ Coincident rate } & $76.9 \%$ & $76.9 \%$ & $69.2 \%$ & $92.3 \%$ & $92.3 \%$ \\
\hline
\end{tabular}

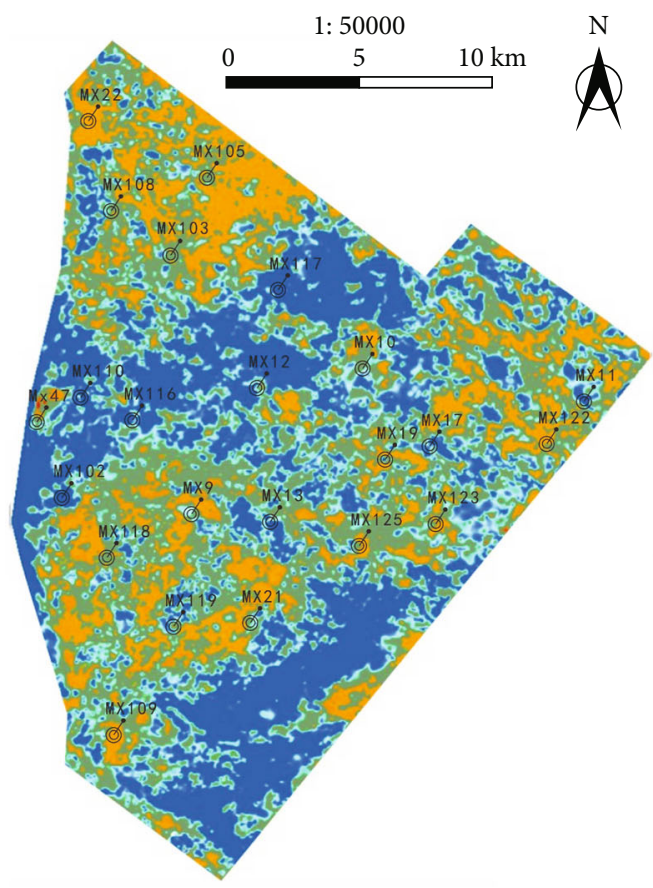

(a)

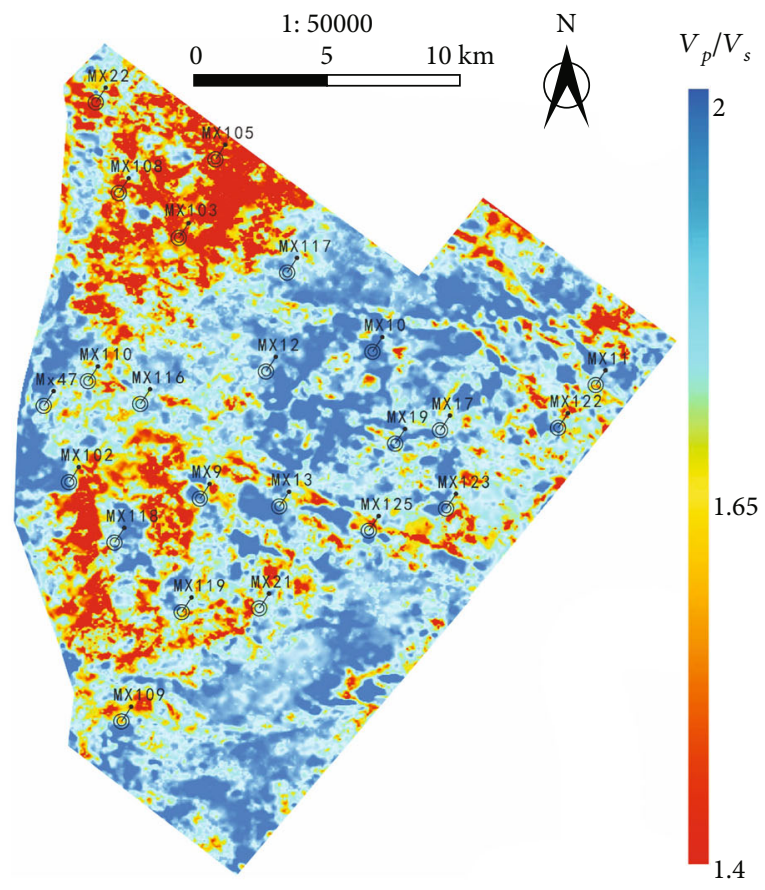

(b)

Figure 15: Planar map of prestack inversion of gas indicator factor (a) and P-S wave velocity ratio (b) of the fourth member of the Dengying Formation.

Based on the inversion results and drilling characteristics, it is concluded that the lower submember of the fourth member of the Sinian Dengying Formation has a small gas thickness and poor reservoir physical properties. The gas-bearing reservoirs are basically distributed in the upper submember of the fourth member of the Dengying Formation. Therefore, the thickness of the upper submember of the fourth member of the Dengying Formation was calculated to obtain the thickness planar of the gas layer in the dolomite reservoir of the Dengying Formation (Figure 16). The thickness of gas reservoir in MX22-MX105 well area is relatively large, which basically shows negative gas-bearing anomaly and low P-S-wave velocity ratio, while the reservoir thickness of low-yielding wells such as MX116, MX12, and MX10 is small, with positive gas-bearing anomaly and high P-Swave velocity ratio. The results show that the thickness of gas-bearing reservoir is highly consistent with the distribution characteristics of gas-bearing property and P-S-wave 


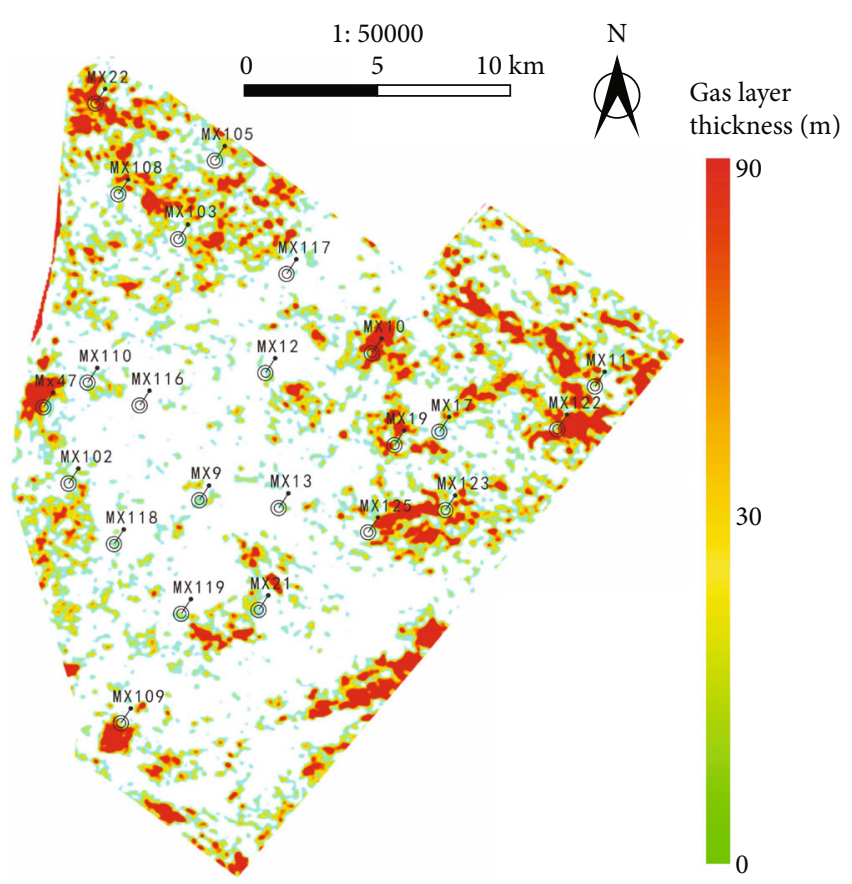

FIGURE 16: Effective thickness distribution of the upper subsegment of the fourth member of Dengying Formation.

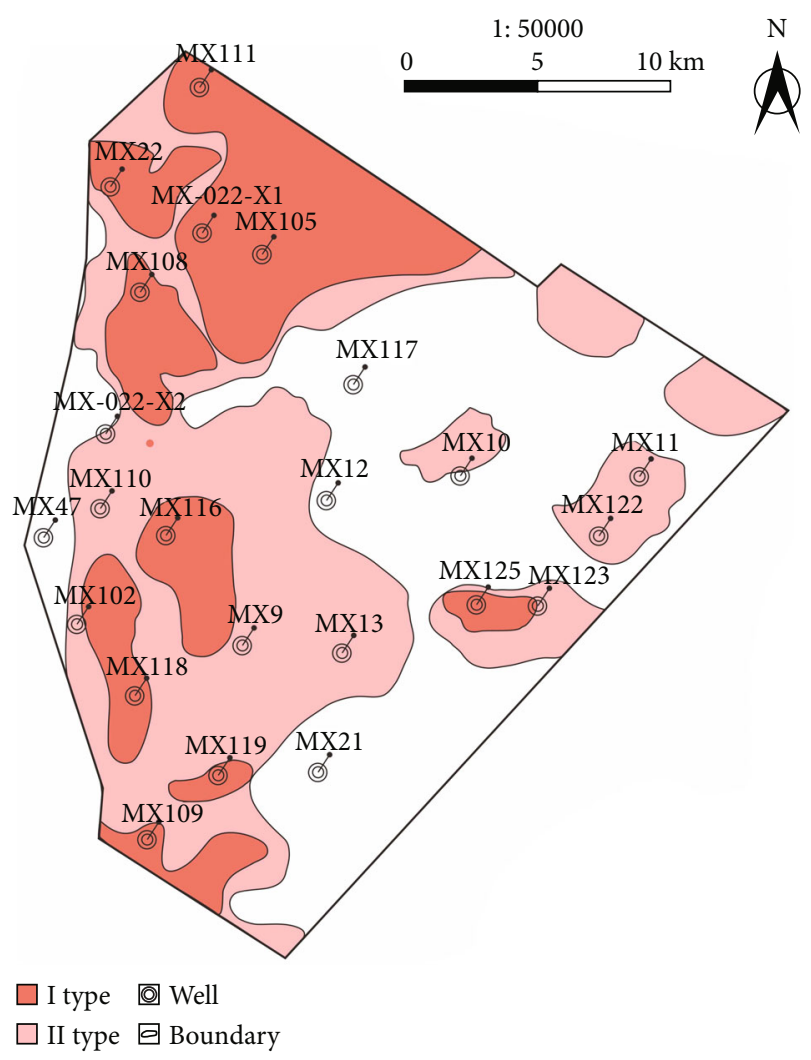

FIGURE 17: Distribution map of favorable target areas in the upper subsegment of the fourth member of Dengying Formation.

velocity ratio. The reservoir in the study area gradually deteriorates from West to East, and the distribution characteristics of point dolomite high-quality reservoirs similar to "sweet spot" distribution are found in the eastern part of the study area (Figures 15 and 16).

Combining the prediction results of different parameters, the study area is divided into two types of favorable target areas. The type I target area mainly contains most of the wells with high gas production. It is located in the high part of the structure, and the thickness of the karst residual mound is large. The prestack inversion $\mathrm{P}$-wave velocity ratio of the type II target area is basically low, and the negative gas-bearing indicator is low. Most of the wells are middle or low-yield wells, and the reservoir physical properties are relatively poor compared to the type I target area (Figure 17).

\section{Conclusion}

In this study, taking the dolomite reservoir of the fourth member of Dengying Formation of Sinian system in Moxi area of Sichuan Basin as an example, AVO forward modeling and prestack inversion are carried out based on prestack seismic data, logging data, and geological information, and the differences of dolomite reservoir identification by various parameters are analyzed. The gas-bearing detection results of prestack simultaneous inversion have the highest coincidence rate with the drilled gas reservoirs. Most of the welldrilled gas layers in the Dengying Formation dolomite reservoirs in the study area belong to type I and type III AVO characteristics. Through comprehensive analysis of drilling and logging data and production data, it is considered that whether the gas reservoir is located at the top of Dengying Formation is the main influencing factor of AVO type. The P-S-wave velocity ratio and fluid factor obtained by prestack simultaneous inversion have the best prediction effect on dolomite reservoir of the fourth member of Dengying Formation in the study area and have a high coincidence with the gas-bearing property and actual drilling results in the study area. The study area is divided into two types of favorable target areas based on the comprehensive P-S-wave velocity ratio, gas indicator factor, and the distribution characteristics of effective reservoir thickness. The type I target area has large reservoir thickness and good gas-bearing properties and is distributed in the western part of the study area. Compared with the type I target area, the reservoir thickness of the type II target area is smaller and the gas-bearing capacity is lower, and it is mostly distributed in the central and eastern regions of the study area.

\section{Nomenclature}

$a$ and $b$ : Empirical parameters, determined according to the actual situation of the study area, dimensionless

GR: $\quad$ Natural gamma, API

$I_{p}: \quad$ P-wave impedance, $\mathrm{m} \cdot \mathrm{g} /\left(\mathrm{cm}^{3} \cdot \mathrm{s}^{-1}\right)$

$I_{s}: \quad$ S-wave impedance, $\mathrm{m} \cdot \mathrm{g} /\left(\mathrm{cm}^{3} \cdot \mathrm{s}^{-1}\right)$

RT: $\quad$ Formation resistivity, $\Omega \cdot \mathrm{m}$

$\mathrm{DEN} / \rho$ : Density, $\mathrm{g} / \mathrm{cm}^{3}$

AC: $\quad$ Interval transit time, $\mu s / \mathrm{m}$

$V_{p}: \quad$ P-wave velocity, $\mathrm{km} / \mathrm{s}$ 
$V_{s}: \quad$ S-wave velocity, $\mathrm{km} / \mathrm{s}$

$\varphi: \quad$ Porosity, \%

$S_{w}: \quad$ Water saturation, $\%$

$\lambda_{\rho}: \quad$ Fluid factor.

\section{Data Availability}

All data, models, and code generated or used during the study appear in the submitted article.

\section{Conflicts of Interest}

The authors declare that they have no conflicts of interest.

\section{Acknowledgments}

The authors thank the National Science and Technology Major Project (2017ZX05008-004-008) for financial support. We appreciate Southwest Oil and Gas Field Company for providing field data. And we would also like to thank CGG for their software support.

\section{References}

[1] L. Zhou, F. Zhong, J. Yan et al., "Prestack inversion identification of organic reef gas reservoirs of Permian Changxing Formation in Damaoping area, Sichuan Basin, SW China," Petroleum Exploration and Development, vol. 47, no. 1, pp. 89-100, 2020.

[2] X. Y. Yin, D. P. Cao, B. L. Wang, and Z. Y. Zong, "Advances in fluid identification based on pre-stack seismic inversion," Oil Geophysical Prospecting, vol. 49, no. 1, pp. 22-34, 2014.

[3] X. Y. Yin, F. C. Zhang, and C. Y. Sun, Pre-Stack Seismic Inversion, China University of Petroleum Press, Dongying, China, 2010.

[4] D. Wang, Z. H. He, and H. Deji, "Research on the method of fluid prediction using angle gathers of pre-stack seismic data-_taking the application in Tahe area as an example," Journal of Oil and Gas Technology, vol. 31, no. 3, pp. 68-71, 2009.

[5] R. T. Shuey, "A simplification of the Zoeppritz equations," Geophysics, vol. 50, no. 4, pp. 609-614, 1985.

[6] P. Connolly, "Elastic impedance," The Leading Edge, vol. 18, no. 4, pp. 438-452, 1999.

[7] D. P. Hampson, B. H. Russell, and B. Bankhead, "Simultaneous inversion of pre-stack seismic data," SEG Annual Meeting, Houston, TX, USA, 2005.

[8] J. L. Fatti, G. C. Smith, P. J. Vail, P. J. Strauss, and P. R. Levitt, "Detection of gas in sandstone reservoirs using AVO analysis: a 3-D seismic case history using the Geostack technique," Geophysics, vol. 59, no. 9, pp. 1362-1376, 1994.

[9] J. X. Han, Pre-Stack Simultaneous Inversion and Application in Reservoir Prediction in Chunguang Oilfield, Chengdu University of Technology, Chengdu, China, 2016.

[10] X. L. Lang, S. B. Peng, H. Q. Kang, Y. Ling, and J. M. Xu, "Application of pre-stack simultaneous inversion in fluid identification," Geophysical Prospecting for Petroleum, vol. 49, no. 2, pp. 164-169, 2010.

[11] L. D. Gan, B. L. Zhao, W. H. Du, and L. G. Liu, "Potential analysis of elastic impedance in lithology and fluid prediction,"
Geophysical Prospecting for Petroleum, vol. 44, no. 5, pp. 504-508, 2005.

[12] M. B. Zhang, S. Q. Shi, and Y. Pan, "The application of prestack inversion technology in Sulige area," Lithologic Reservoirs, vol. 19, no. 4, pp. 91-94, 2007.

[13] Y. G. Chang, Z. H. Zhang, Z. M. Wang, and Z. Y. Zheng, "Analysis of the application effect of elastic impedance inversion in volcanic rock development area: a case study of Nanpu structure in Tanhai area of Jidong province," Natural Gas Geoscience, vol. 18, no. 3, pp. 422-425, 2007.

[14] D. Shelander, J. Dai, and G. Bunge, "Predicting saturation of gas hydrates using pre-stack seismic data, Gulf of Mexico," Marine Geophysical Researches, vol. 31, no. 1-2, pp. 39-57, 2010.

[15] X. Y. Li, "A discussion on the technical difficulties and countermeasures to carry out seismic exploration in the carbonate rock areas of Sichuan Basin," Natural Gas Industry, vol. 20, no. 2, pp. 12-17, 2000.

[16] L. Zhou, B. B. Ren, Y. Wu et al., "The seismic response feature and the distribution prediction of oolitic beachs of Feixianguan formation in the northern Sichuan Basin," Chinese Journal of Geology, vol. 51, no. 2, pp. 425-447, 2010.

[17] L. Zhou, B. Yuan, Y. Song et al., "A seismic quantitative identification method of slope break belt," Petroleum Exploration and Development, vol. 43, no. 6, pp. 940-948, 2016.

[18] Y. Neng, H. J. Yang, and X. L. Deng, "Structural patterns of fault broken zones in carbonate rocks and their influences on petroleum accumulation in Tazhong Paleo-uplift, Tarim Basin, NW China," Petroleum Exploration and Development, vol. 45, no. 1, pp. 40-50, 2018.

[19] M. Jin, X. Tan, M. Tong et al., "Karst paleogeomorphology of the fourth member of Sinian Dengying Formation in Gaoshiti-Moxi area, Sichuan Basin, SW China: restoration and geological significance," Sichuan Basin. Petroleum Exploration and Development, vol. 44, no. 1, pp. 58-68, 2017.

[20] X. W. Tian, D. L. Yang, J. Y. Zhong et al., "Micro-characterization of dolomite reservoir based on CT imaging technology-_taking Moxi in Sichuan - an example of the fourth member of the Sinian Dengying Formation in the Longnüsi Ini-Taiwan area," Acta Sedimentologica Sinica, no. 55, pp. 1-14, 2020.

[21] B. Luo, Y. M. Yang, W. J. Luo et al., "Reservoir development control factors and distribution of Dengying formation in central Sichuan paleo-uplift," Acta Petrolei Sinica, vol. 36, no. 4, pp. 416-426, 2015.

[22] C. X. Xu, P. S. Ma, L. B. Lai et al., "Gas-bearing sensitivity parameters of tight sandstones: taking Yingcheng formation of Yingtai gas field in Songliao Basin as an example," Petroleum Exploration and Development, vol. 41, no. 6, pp. 712716, 2014

[23] L. X. Li, X. Y. Yin, D. P. Cao, and X. J. Liu, "Methodology and application of oil/water identification based on fluid factor pre-stack seismic inversion," Computerized Tomography Theory and Applications, vol. 25, no. 1, pp. 33-40, 2016.

[24] Y. Y. Zhang, Z. D. Sun, J. F. Han, H. Y. Wang, and C. Y. Fan, "Fluid mapping in deeply buried Ordovician paleokarst reservoirs in the Tarim Basin, western China," Geofluids, vol. 16, no. 3, 433 pages, 2016.

[25] W. Sun, C. C. Yang, S. H. Ma, and B. T. Li, "Prediction method of S-wave velocity," Progress in Geophysics, vol. 23, no. 2, pp. 470-474, 2008. 
[26] X. Wang, W. J. Li, L. M. He, Y. C. Wang, and X. Zhang, "Swave estimation quality control method," Journal of Oil and Gas Technology, vol. 33, no. 9, pp. 87-91, 2011.

[27] S. S. Zhou, W. Yi, Z. B. Hao, W. Q. Huang, and X. Y. Wu, "Experiment research and application of fluid sensitive attributes based on the pre-stack inversion," Chinese Journal of Geophysics, vol. 55, no. 6, pp. 1985-1992, 2012.

[28] M. F. Gu, M. R. Xu, J. G. Zhou, C. Ni, Y. Xin, and Y. Hao, "Application of pre-stack simultaneous inversion to the prediction of carbonate reservoirs," Lithologic Reservoirs, vol. 25, no. 2, pp. 60-64, 2013.

[29] B. Goodway, T. W. Chen, and J. Downton, "Improved AVO fluid detection and lithology discrimination using Lamé petrophysical parameters: " $\lambda \rho$ ", “ $\mu \rho$ ", \& “ $\lambda / \mu$ fluid stack", from $P$ and S inversion," SEG Technical Program Expanded Abstracts, Houston, TX, USA, 1997.

[30] H. D. Huang, Y. C. Wang, F. Guo, S. Zhang, Y. Z. Ji, and C. H. Liu, "Zoeppritz equation-based pre-stack inversion and its application in fluid identification," Applied Geophysics, vol. 12, no. 2, pp. 199-211, 2015.

[31] S. H. Zhang, "Analysis of rock-physical properties through angle-gather profiles," Journal of Xi'an Shiyou University, vol. 22, no. 5, pp. 18-20, 2007.

[32] Z. Y. Fang, J. M. Zhu, Y. Li, L. N. Huang, and J. S. Li, “The method and application of synchronous pre-stack seismic inversion," Journal of Chengdu University of Technology, vol. 41, no. 2, pp. 152-156, 2014.

[33] J. Z. Liu, Z. D. Sun, Z. T. Liu, Y. Y. Sun, N. Dong,, and H. M. Xia, "Application of simultaneous pre-stack inversion in the identification of carbonate reservoir fluids_- taking area 6 and area 7 of Tahe oilfield as examples," Lithology Oil and Gas Reservoirs, vol. 27, no. 1, pp. 102-107, 2015.

[34] W. D. Li, Reservoir prediction based on simultaneous pre-stack inversion: taking the He 8 member of Sulige gas field as an example, China University of Geosciences, 2016.

[35] Y. H. Yang, G. Gao, H. M. Wei, J. Z. Zhang, and Z. X. Gui, "Application of simultaneous pre-stack inversion to identify reservoirs and fluids in gray matter development areas," Progress in Geophysics, vol. 32, no. 1, pp. 332-338, 2017. 